\title{
KOMPARASI EFFISIENSI PENGEREMAN PENGUJIAN REM STATIS (STATIC BRAKE TEST) DAN PENGUJIAN REM JALAN (ROAD BRAKE TEST)
}

\author{
Ethys Pranoto' ${ }^{1}$ Aziz Miftahul Hidayat ${ }^{2}$, Faris Humami ${ }^{3}$, M Iman Nur Hakim ${ }^{4}$ \\ 1,3 Program Studi Teknik Keselamatan Otomotif \\ 2,4 Program Studi Pengujian Kendaraan Bermotor \\ Politeknik Keselamatan Transportasi Jalan \\ Jalan Semeru No.3 Kota Tegal, Jawa Tengah 52125 \\ E-mail: ethysp@yahoo.com
}

\begin{abstract}
Abstrak
Keselamatan dan keamanan berkendara di jalan menjadi unsur utama dalam pelayanan jasa transportasi. Penyedia pelayanan jasa transportasi berkewajiban memastikan bahwa kendaraan yang dioperasikan memenuhi syarat teknis dan laik jalan kendaraan bermotor yang ditentukan oleh pemerintah. Salah satu syarat teknis dan laik jalan adalah terpenuhinya sistem rem yang berfungsi dan memenuhi ambang batas. Pengujian untuk memenuhi ambang batas dapat dilakukan dengan dua metode yaitu Static Brake Test dan Road Brake Test. Kedua metode yang berbeda akankah menghasilkan keluaran yang sama. Hasil komparasi kedua pengujian menunjukkan adanya perbedaan keluaran yang diperoleh dan hal ini dapat menimbulkan persepsi yang berbeda terhadap pemenuhan syarat teknis dan laik jalan kendaraan.
\end{abstract}

Kata kunci: Efisiensi Rem, Static Brake Test, Road Brake Test

\section{PENDAHULUAN}

Kecelakaan lalu lintas merupakan kejadian yang tidak diharapkan dalam transportasi. Risiko kecelakaan dapat dikurangi dengan memastikan bahwa faktor penyebab kecelakaan baik sarana, prasarana dan pengguna dalam kondisi baik. Pesatnya pertumbuhan penduduk dan meningkatnya kebutuhan pelayanan jasa transportasi menuntut adanya peningkatan unsur keselamatan dalam penyediaan jasa transportasi baik secara kuantitatif maupun kualitatif. Kondisi baik dan upaya peningkatkan unsur keselamatan dan keamanan pada aspek sarana jika sarana yang dioperasikan memenuhi pesyaratan teknis dan laik jalan yang telah ditetapkan oleh pemerintah.

Rem diklasifikasikan menurut rem yang biasanya terdapat dan digunakan pada kendaraan bermotor yaitu rem utama (service brakes) berupa rem kaki yang digunakan untuk pengereman dalam keadaan normal, rem parkir (parking brakes) yang digunakan kendaraan saat kondisi diam/parkir, dan rem tambahan (secondary or emergency brakes) yang digunakan untuk menjaga apabila terjadi kegagalan sebagian pada sistem rem. Dalam praktek saat ini, beberapa komponen yang digunakan pada rem utama juga digunakan pada sistem rem parkir dan sistem rem sekunder/tambahan.

Sistem pengereman (brake system) sangat mutlak diperlukan pada setiap kendaraan, karena memiliki fungsi untuk mengurangi kecepatan atau menghentikan kendaraan sehingga berperan juga sebagai perangkat keselamatan pengemudi di dalam 
berkendara. Umumnya rem bekerja karena adanya sistem gabungan penekanan yang melawan sistem gerak putar roda. Media yang digunakan untuk penekanan tersebut dapat berupa minyak rem (hydraulic brake), udara bertekanan (air brake) atau kombinasi antara kedua media tersebut. (air over hydraulic brake).

Pengujian rem utama dilakukan pada kendaraan tanpa muatan atau dengan sarat muatan akan memberikan indikasi kinerja pengereman kendaraan dalam konfigurasi yang diuji. Jika ada perubahan pada konfigurasi kendaraan, seperti penambahan muatan, distribusi perubahan muatan, atau konfigurasi beban kombinasi beragam, maka konfigurasi baru lebih lanjut akan diperlukan dalam pengujian.

Dalam menentukan lulus uji suatu kendaraan bermotor, salah satu item pengujian yang harus dilaksanakan adalah pengujian rem yang bertujuan untuk mengetahui efisiensi rem utama dan rem parkir.

Peraturan Pemerintah No 55 Tahun 2012 tentang kendaraan.Pasal 67 (1) Efisiensi sistem rem sebagaimana dimaksud dalam Pasal 64 ayat (2) huruf $c$ dan huruf $d$ harus memenuhi hasil pengukuran dengan perlambatan paling sedikit 5 (lima) meter per detik kuadrat.

Persamaan umum untuk menghitung kinerja/performa rem yaitu perlambatan ( $d$ ) berasal dari hukum Newton ke-II yakni dengan menghitung gaya-gaya yang bekerja pada kendaraan di sepanjang sumbu-x. Gaya-gaya yang bekerja pada kendaraan dapat ditunjukkan pada Gambar 1 ini:

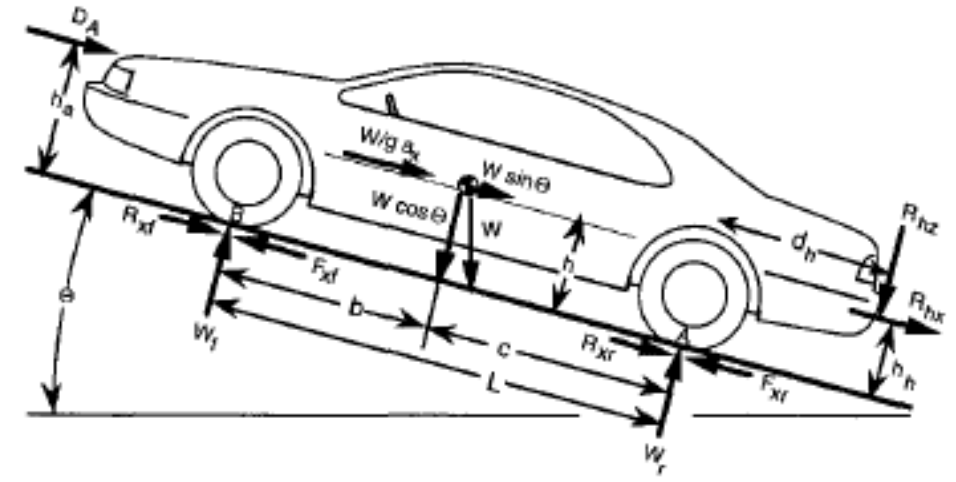

Gambar 1. Gaya-gaya yang bekerja pada kendaraan bermotor

Perlambatan merupakan fenomena yang dihasilkan akibat adanya aksi pengereman yang arahnya berlawanan (negatif) dengan arah percepatan kendaraan. Selama proses pengereman akan terjadi gesekan. Semakin besar gesekan tersebut terjadi maka akan semakin besar pula perlambatan yang dihasilkan. Perlambatan maksimum terjadi pada koefisien gesek maksimum antara ban dengan permukaan jalan (sesaat sebelum terjadi locking pada ban kendaraan). Bila diasumsikan bahwa gaya-gaya yang bekerja pada kendaraan besarnya konstan selama proses pengereman maka persamaan yang menunjukkan besarnya perlambatan akibat aksi pengereman adalah:

Keterangan :

$$
D_{x}=\frac{F_{x t}}{M}
$$

$D_{x}=$ perlambatan dalam arah- $\mathrm{x}\left(\mathrm{m} / \mathrm{s}^{2}\right)$

$F_{x t}=$ total gaya rem yang bekerja pada kendaraan dalam arah-x (Newton)

$M=$ massa total kendaraan + muatan $(\mathrm{kg})$

Traksi/gaya pengereman adalah kemampuan ban pada kendaraan untuk menyediakan 
gaya gesek (friction) atau dengan kata lain adalah besarnya gaya gesek antara ban dan permukaan jalan. Nilai traksi/gaya yang tersedia bervariasi bergantung pada kondisi permukaan jalan, pola kembang ban kendaraan, material ban, dan berat kendaraan. Berat kendaraan akan mempengaruhi nilai traksi/gaya rem pada saat terjadi weight transfer sehingga nilainya dapat bervariasi.

$$
F_{b}=\mu \cdot N
$$

Torsi pengereman adalah besarnya gaya gesek pada ban yang dikalikan dengan rolling radius pada ban tersebut. Torsi pengereman dapat dikatakan pula sebagai kekuatan pengereman (braking power) atau braking capacity.

$$
T=F_{b} \cdot R
$$

Berikut ini adalah diagram benda bebas kendaraan ketika mengalami kecepatan konstan dan perlambatan:

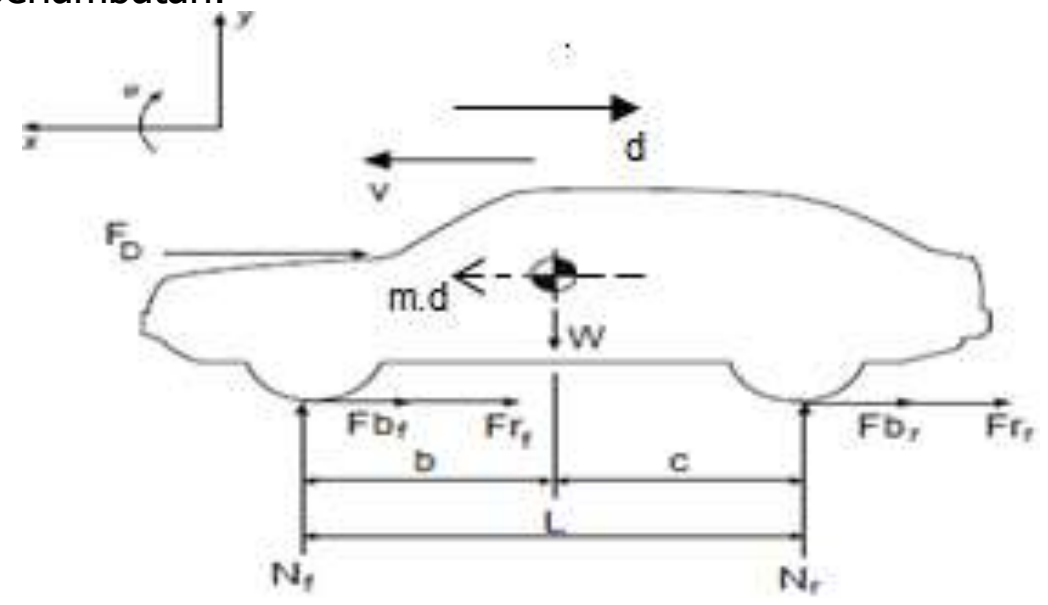

Gambar 2. Diagram benda bebas kendaraan

Jika diketahui $F b_{f, r}$ adalah gaya pengereman di roda depan dan belakang, $F r_{f, r}$ adalah rolling resistance di roda depan dan belakang, $F_{D}$ adalah gaya aerodinamis drag, $V$ adalah kecepatan kendaraan $(\mathrm{m} / \mathrm{s}), N_{f, r}$ adalah gaya normal di roda depan dan belakang, $W$ adalah berat kendaraan dan muatan, dan $m . d$ adalah gaya inersia perlambatan kendaraan (Newton)

\section{Tes Rem Statis}

Uji efisiensi rem statis dilakukan pada alat yang mengukur gaya pengereman horizontal pada setiap roda. Gaya-gaya ini kemudian ditambahkan bersama untuk memberikan gaya pengereman horizontal total untuk kendaraan; gaya total ini kemudian dibagi dengan bobot kendaraan untuk memberikan efisiensi pengereman kendaraan dalam kondisi tempat pengujian.

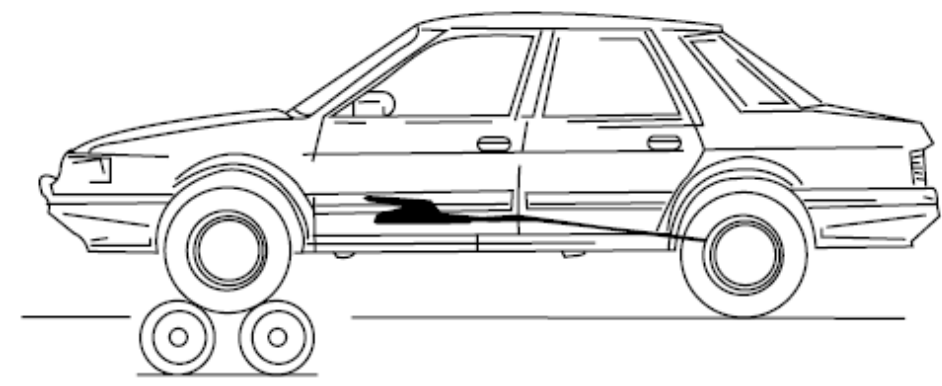

Gambar 3. Uji Rem Statis 
Untuk menghitung efisiensi rem utama $(\eta \mathrm{Sb})$ pada uji rem statis :

$$
\eta S b=\frac{\text { Jumlah gaya rem pada sumbu }(S 1+S 2)}{\text { Berat Kendaraan }} \times 100 \%
$$

Tes Rem Jalan

Uji efisiensi rem jalan dilakukan pada jalan dimana kendaraan dipacu dengan kecepatan tertentu kemudian pada titik tertentu dilakukan pengeraman secara kuat. Titik awal pengereman dan titik akhir pengereman dicatat sbagai jarak pengereman, $s$. Selain dipeoleh hasil jarak penegereman perlu dicatat juga kecepatan awal, $V_{o}$ dan kecepatan akhir, $V_{t}$ seperti gambar 4 .

$$
\begin{gathered}
V_{t}=V_{o} \pm a \cdot t \\
S=V_{o} \cdot t \pm \frac{1}{2} a \cdot t^{2}
\end{gathered}
$$

Dengan menurunkan persamaan Gerak Lurus Berubah Beraturan (GLBB) diperoleh nilai perlambatan, a sebesar:

$$
a=\frac{1}{2} \frac{\left(V_{t}-V_{o}\right)^{2}}{S}
$$

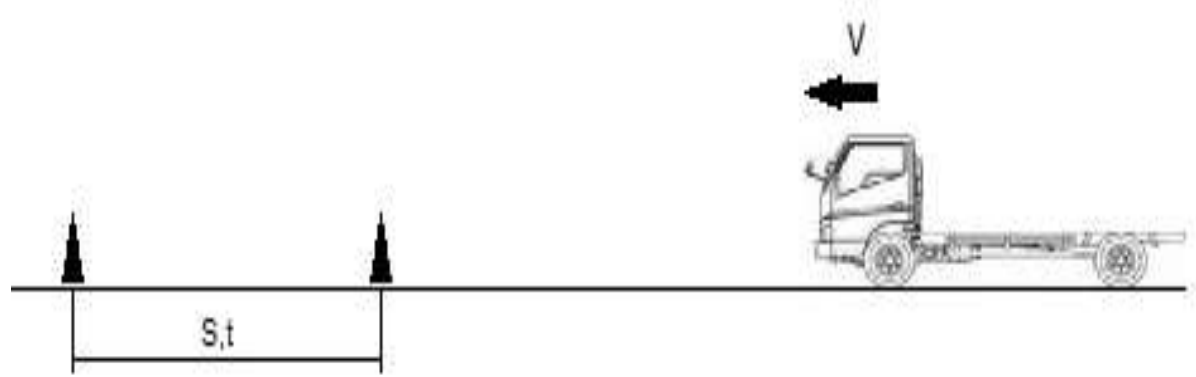

Gambar 4. Tes Rem Jalan

Jika diketahui $a$ adalah nilai pengereman $\left(m . s^{-2}\right), V_{t}$ adalah kecepatan akhir kendaraan $\left(\mathrm{m} . \mathrm{s}^{-1}\right), V_{o}$ adalah kecepatan awal kendaraan $\left(\mathrm{m} . \mathrm{s}^{-1}\right)$, Sadalah jarak pengereman, $(\mathrm{m})$. Nilai perlamabatan akan bernilai negatif.

Efisiensi pengereman

Kekuatan sistem pengereman pada akhirnya ditentukan oleh gesekan antara ban dan permukaan penggerak. Konsep efisiensi pengereman didasarkan pada asumsi bahwa koefisien gesekan antara ban dan permukaan penggerak tidak pernah lebih besar dari 1. Gambar 5 menunjukkan kendaraan dengan roda yang dikunci oleh rem yang ditarik secara horizontal oleh gaya yang sama dengan berat kendaraan. Keterhambatan yang dicapai dalam kondisi seperti itu sama dengan percepatan gravitasi $\mathrm{g}=9.81 \mathrm{~m} . \mathrm{s}^{-2}$ dan ini dianggap sebagai efisiensi pengereman 100\%. Jika retardasi aktual kendaraan dengan pengereman adalah $\mathrm{m} . \mathrm{s}^{-2}$, efisiensi pengeremannya adalah a/g $\times 100 \%$. 


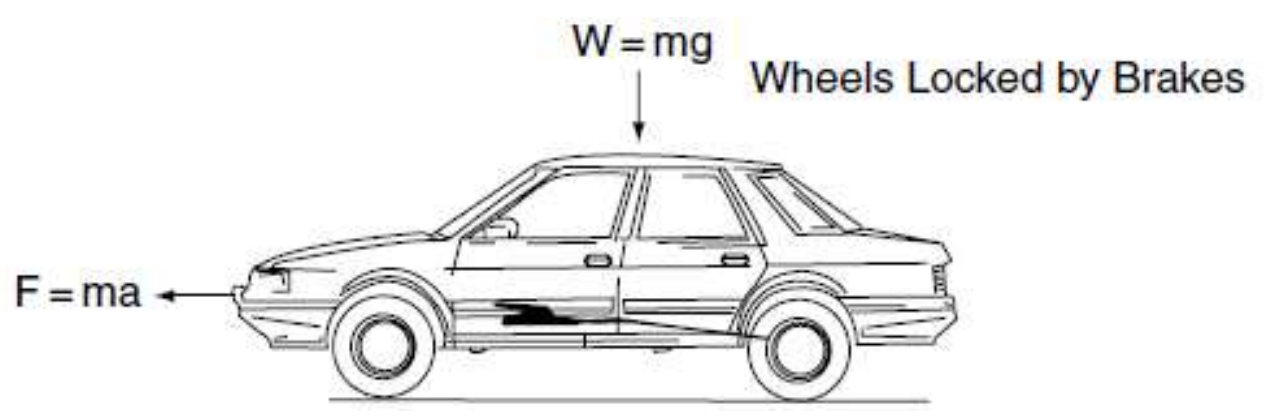

Gambar 5. Efisiensi Pengereman

\section{METODE PENELITIAN}

Pengujian uji rem statis dan uji rem jalan dilakukan dengan menggunakan kendaraan Hino Dutro Chasis 110LD dengan spesifikasi kendaraan sebagai berikut

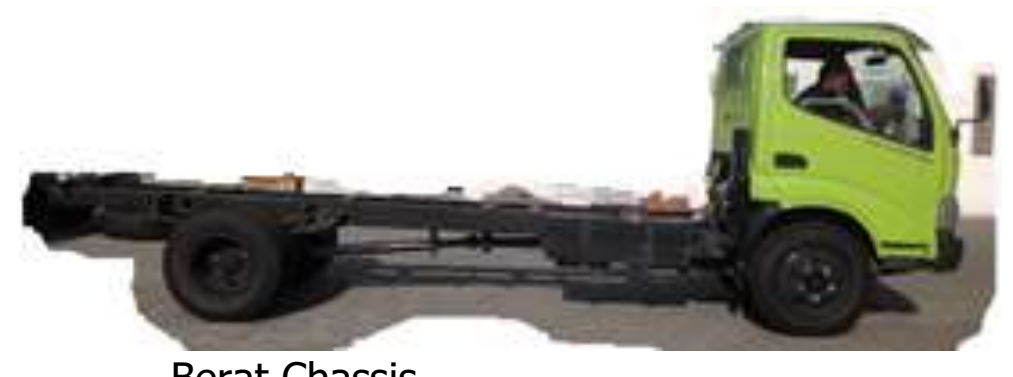

Berat Chassis

$\begin{array}{llr}\text { Depan } & (\mathrm{kg}) & 1365 \\ \text { Belakang } & (\mathrm{kg}) & 782 \\ \text { Total } & (\mathrm{kg}) & 2147 \\ \text { GVWR } & (\mathrm{kg}) & 7000\end{array}$

Gambar 6. Spesifikasi Dutro Chasis 110LD

Selain spesifikasi pada gambar 6, dipastikan kondisi tekanan ban dan alur ban sesuai ketentuan. Alat uji rem roller menggunakan ACTIA MULLER seperti gambar 7, dengan koefisien grip roller $>0.8$ pada kondisi kering.
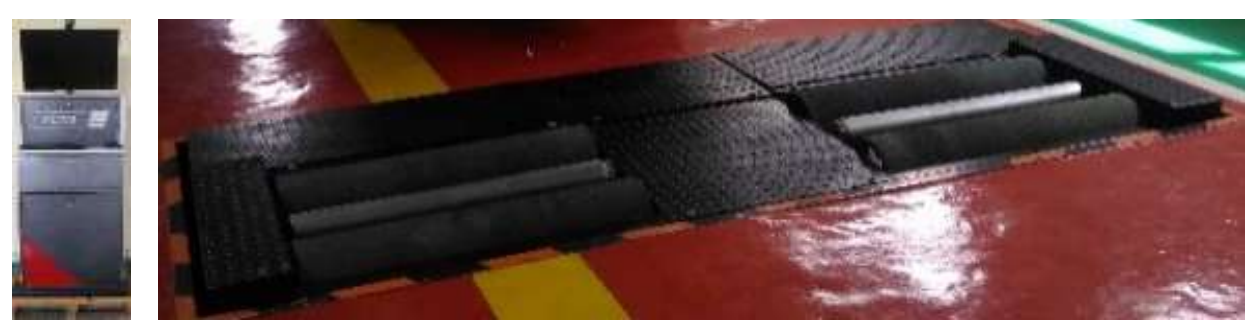

Gambar 7. Alat Uji Rem Roller ACTIA

Lokasi uji rem jalan dilakukan pada jalan dengan perkerasan aspal sepanjang $300 \mathrm{~m}$. Kendaraan dipacu pada kecepatan 40 km/jam kemudian dilakukan pengereman hingga roda mengalami penguncian (lock brake). Pengereman dilakukan sampai kendaraan berhenti atau $V_{t}=0$. 


\section{HASIL DAN PEMBAHASAN}

Hasil pengujian Static Roller Brake Test didapatkan data seperti tabel 1 berikut;

Tabel 1. Hasil Uji Rem Statis

\begin{tabular}{ccccc}
\hline \multicolumn{2}{c}{$\begin{array}{c}\text { Gaya Pengereman } \\
\text { (daN) }\end{array}$} & \multicolumn{2}{c}{$\begin{array}{c}\text { Berat Kendaraan } \\
\text { (daN) }\end{array}$} & $\eta(\%)$ \\
S1 & S2 & S1 & S2 & \\
\hline 972 & 370 & 1434 & 739 & 62 \\
921 & 438 & 1434 & 729 & 63 \\
952 & 525 & 1444 & 729 & 68 \\
999 & 534 & 1419 & 739 & 71 \\
1002 & 517 & 1394 & 724 & 72 \\
\hline
\end{tabular}

Berdasarkan data tabel 1 dan persamaan perhitungan efisiensi rem diperoleh rata-rata efisiensi pengereman sebesar $76.2 \%$.

Hasil pengujian Road Brake Test didapatkan data seperti tabel 2 berikut;

Tabel 2. Hasil Tes Rem Jalan

\begin{tabular}{ccc}
\hline $\begin{array}{c}\text { Jarak Pengereman } \\
\mathbf{( m )}\end{array}$ & Perlambatan $\left(\mathbf{m . s}^{\mathbf{- 2}}\right)$ & $\eta(\mathbf{\%})$ \\
\hline 13.41 & 4.60 & 47 \\
13.32 & 4.63 & 47 \\
12.05 & 5.12 & 52 \\
11.21 & 5.50 & 56 \\
11.15 & 5.53 & 56 \\
\hline
\end{tabular}

Tabel 2 merupakan data hasil uji rem jalan dengan megemudikan kendaraan dengan kecepatan awal $40 \mathrm{~km} / \mathrm{jam}$ dan diperoleh data jarak penegereman. Perlambatan diperoleh berdasarkan perhitungan persamaan percepatan tes rem jalan. Dari data tersebut diperoleh rata-rata efisiensi pengereman tes rem jalan sebesar $51.4 \%$.

Berdasarkan hasil uji efisiensi rem terdapat perbedaan yang signifikan. Perbedaan ini dapat terjadi karena perbedaan faktor yang mempengaruhi ketika proses pengujian. Dalam penelitan ini ada perbedaan hasil yang dapat disebabkan perbedaan sifat adesif antara ban dan roller atau jalan yang ditentukan oleh koefisien gesek atau grip dari roller atau jalan. Data yang didapatkan koefisien gesek dari jalan yang digunakan tes rem jalan sebesar 0.66 setelah diukur menggunakan Airport Surface Friction Tester T2Go sedangkan koefisien grip roller sebesar 0.8 . Kendaraan yang sama dengan sistem rem dalam kondisi sempurna dapat lulus atau gagal dalam uji rem, tergantung pada proses pengujian yang mana dipengaruhi oleh faktor jarak antar rol, atau tergantung pada kekasaran rol dengan tekanan ban yang sama.

\section{PENUTUP}

\section{Simpulan}

1. Kendaraan yang diuji rem baik dengan uji rem statik dan uji rem jalan adalah memastikan bahwa kondisi sistem pengereman dalam kondisi baik. Kondisi baik diharapkan memenuhi persyaratan teknis dan laik jalan kendaraan bermotor.

2. Dua metode dapat disimpulkan dapat untuk menentukan nilai efisiensi pengereman, namun ada perbedaan hasil nilai efisiensi pengereman. Oleh karena 
itu harus memperhatikan faktor yang mempengaruhinya seperti nilai adesif antara roda dan permukaan rol atau jalan.

3. Nilai koefisien adesif yang berbeda dapat mempengaruhi hasil efisiensi pengereman, semakin tinggi nilai koefisien adesif semakin tinggi efisiensi

Saran pengeremannya.

Untuk mendapatkan hasil yang lebih baik dalam hal ini perlu penelitian lanjut dengan memperhatikan faktor-faktor yang mempengaruhi efisiensi pengereman, seperti variasi jenis kendaraan, permukaan jalan dan alat uji rem.

\section{DAFTAR PUSTAKA}

Limpert, R. (1999). Brake Design and Safety (2nd ed.). Warrendale: Society of Automotive Engineers, Inc.

National Heavy Vehicle Regulator, (2018). National roller brake testing Procedure.

Pemerintah Republik Indonesia (2012) Peraturan Pemerintah Nomor 55 tahun 2012 tentang kendaraan

Gillespie, T. D. (1992). Fundamental of Vehicle Dynamics. Warrendale: Society of Automotive Engineers, Inc.

Crolla, D. A. (2009). Automotive Engineering: Powertrain, Chasis System and Vehicle Body (1st ed.). Burlington, USA: Elsevier Inc.

Bonnick, Allan (2008). Automotive Science and Mathematics, Butterworth-Heinemann

C. Senabre, E. Velasco and S. Valero, (2015). Differences in Brake Data Results on Ministry of Transport Roller Bank Testers Such as: Maha, Ryme, with Different Distance between Rollers and Roughness of Rollers, Journal of Mechanics Engineering and Automation. 